\title{
Sympatric Distribution of the Two Morphological Types of the Common Tree Shrew in Hat-Yai Districts (South Thailand)
}

\author{
Hideki ENDO, Yoshihiro HAYASHI ${ }^{1)}$, Worawut RERKAMNUAYCHOKE ${ }^{2)}$, Nivesh NADEE ${ }^{3)}$, Jarujin \\ NABHITABHATA $^{4)}$, Yoshi KAWAMOTO ${ }^{5}$, Hirohisa HIRAI $^{5}$, Junpei KIMURA ${ }^{6}$, Takao NISHIDA ${ }^{7}$ and \\ Junzo YAMADA ${ }^{8)}$
}

Department of Zoology, National Science Museum, Tokyo, Shinjuku-ku, Tokyo 169-0073, '1)Department of Veterinary Anatomy, Graduate School of Agricultural and Life Sciences, The University of Tokyo, Tokyo, Japan, ${ }^{2)}$ Department of Veterinary Anatomy, Kasetsart University, Bangkok, ${ }^{3)}$ Energy and Environment Research Department, Thailand Institute of Scientific and Technological Research, Bangkok, ${ }^{4)}$ Reference Collection Division, National Science Museum, Thailand, Bangkok, Thailand, ${ }^{5)}$ Primate Research Institute, Kyoto University, Aichi, ${ }^{6}$ Department of Veterinary Anatomy, and ${ }^{7)}$ Anatomy and Physiology, College of Bioresource Sciences, Nihon University, Kanagawa, and ${ }^{8)}$ Department of Veterinary Anatomy, Obihiro University of Agriculture and Veterinary Medicine, Obihiro, Japan

(Received 14 December 1999/Accepted 1 March 2000)

ABSTRACT. The two color types (grayish northern and reddish southern types) of the common tree shrew (Tupaia glis and Tupaia belangeri) were co-distributed in Hat-Yai region (South Thailand). Although the Isthmus of Kra in South Thailand has been considered as distribution barrier of the two types, the sympatric distribution of both types was confirmed in southern side of the Isthmus. In the principal component analysis, the skull measurement character from Hat-Yai region could also be separated into the northern and southern groups according to the skin color identification of corresponding individuals. We could generally distinguish the common tree shrew into two types by skull morphology as well as external skin color.

KEY WORDS: Isthmus of Kra, Tupaia belangeri, Tupaia glis.

The common tree shrew complex of the two external skincolor variations (so-called Tupaia belangeri and Tupaia glis in Wilson and Reeder [9]) is distributed in the Indomalayan and South Asian regions [2, 6]. The Isthmus of Kra in South Thailand (Fig. 1) has been considered as distribution barrier in the two variations $[1-5,8]$ and it has been suggested that the grayish-colored northern type and the reddish-colored southern type are zoogeographically split by the Isthmus of Kra. However, the local distribution of the two variations has not been detailed closer to the Isthmus.

In Hat-Yai Districts (at 7 degree north latitude), the south area close to the Isthmus of Kra (at 10 degree north latitude) (Fig. 1), we collected 7 specimens of the tree shrews (Table 1), described the skin color and measured the skulls. To compare the skull measurements, we used a total of 159 adult skull specimens (Table 1), which have been stored in Thailand Institute of Scientific and Technological Research (Bangkok, Thailand), Department of Wildlife and National Parks (Kuala Lumpur, Malaysia), Forschungsinstitut und Naturmuseum Senckenberg (Frankfurt am Main, Germany), Muséum National d'Histoire Naturelle (Paris, France), and Department of Zoology, National Science Muséum, Tokyo (Tokyo, Japan). We have not obtained the skin color data of each skull specimen. Although the skull measurement data have also been used in the previous reports $[4,5]$, the specimens from Peninsula Thailand to Thailand-Malaysian border around Isthmus of Kra were rejected in this study, because sympatry and co-distribution of the two types were supposed there. The methods and items of measurement and principal component analysis have been explained in the previous reports $[4,5]$.
The external color in 7 specimens from Hat-Yai was obviously distinguished into two variations: the grayish-colored northern type and the reddish-colored southern type (Table 1). The dorsal side was red or cinnamon in color, whereas the ventral side was light brown or brown-gray in the reddish-colored type individuals. The reddish-colored type showed the dark facial line, buff shoulder stripe and had dark red fur in tail. In the grayish-colored type animals, the dorsal side was dark green or dark gray, and ventral side was buff and sandygray. The shoulder stripe was light gray, the tail was black or dark gray, and the short black facial line was shown in both sides rostral to the eyes in the grayish variation.

According to the taxonomical identification of Lyon [7], we think that Tupaia chinensis and Tupaia belangeri belong to the grayish type, whereas the Tupaia lacernata wilkinsoni and Tupaia glis ferruginea correspond to reddish variation. Lyon described that the southern type is grizzled, ferruginous or chestnut and blackish, and that the northern population is grizzled, buff and blackish. The detailed split at species or subspecies level by Lyon may not be effective in comparison with our data. Lyon [7] considered the Isthmus of Kra at 10 degree and the point at 7.5 degree north latitude as border lines of the different color types, and pointed out that Tupaia lacernata wilkinsoni occupies the Hat-Yai area. However, we suggest that the sympatry of the two color types is observed in the region between the Isthmus of Kra and the Hat Yai District.

We drew the principal component (PC) plots, $\mathrm{PC} 1$ against PC2 in males (Fig. 2) and in females (Fig. 3), respectively. The southern population points were mainly plotted in posi- 
tive area of the first principal component, and in negative region of the second principal component. Although the skin color of the corresponding skulls has not been examined in museum specimens, the plots of the museum samples could be basically separated into the northern and southern groups, and the results were consistent with the specimen locality data. The Hat-Yai sample could be completely divided into the two

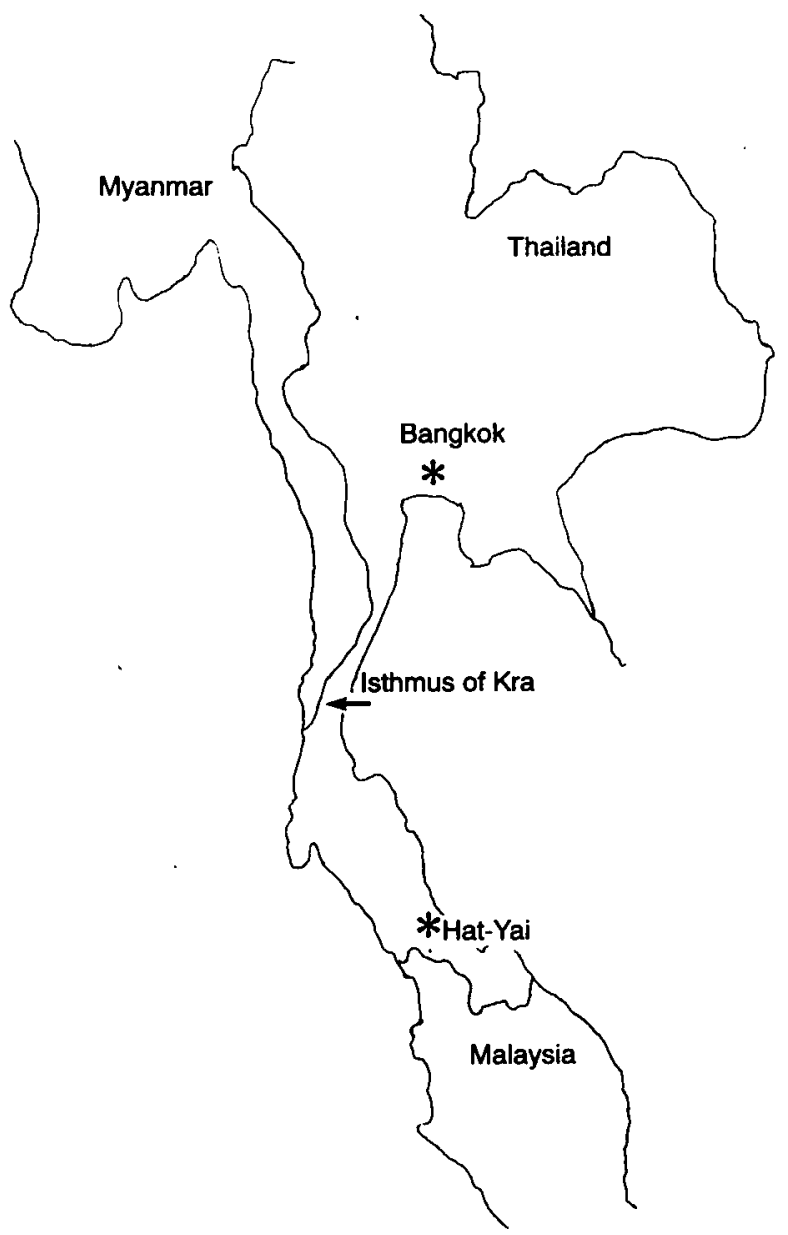

Fig. 1. Map of Thailand indicating the location of the Isthmus of Kra (arrow). Hat-Yai town is located in southern side of the Isthmus in Peninsula Thailand. groups. The grayish individual data were plotted in the northern group, whereas reddish ones were distributed within southern one. The Hat-Yai sample was relatively small in size in both variations and sexes (Figs. 2 and 3). The small-size tendency in skull from Hat-Yai should be geographically examined using larger sample size in future.

We examined the coefficients of linear discriminant function in this separation problem, and demonstrated that the two populations can be statistically distinguished in the $F$-test of the difference between groups [5]. In this study, we can point out that the two color types of common tree shrew are sympatric at least in Hat-Yai region. Furthermore, in the principal component analysis, the skull measurement character from sympatric region could also be separated and included into the northern and southern groups according to the skin color identification of corresponding individuals.

We will undertake the mitochondrial DNA sequence analysis, and examine the blood serum protein polymorphisms in these two groups to discuss the assumptive occurrence of hybrid population between the two types in the sympatric area in future. The status of the speciation has remained unclear between these two groups. However, at least, it was demonstrated that the separable character could be morphologically recognized in Hat-Yai region. It is suggested that the distribution area of the northern grayish type may extend into the southern region beyond the Isthmus of Kra.

\section{REFERENCES}

1. Arrighi, F. E. 1969. Cytogenetics 8: 199-208.

2. Boonsong, L. and McNeely, J. A. 1988. Mammals of Thailand, 2nd ed., Saha Karn Bhaet, Co., Bangkok.

3. Corbet, G. B. and Hill, J. E. 1992. The Mammals of the Indomalayan Region: A Systematic Review. Oxford Univ. Press, Oxford.

4. Endo, H., Cuisin, J., Nadee, N., Nabhitabhata, J., Suyanto, A., Kawamoto, Y., Nishida, T. and Yamada, J. 1999. J. Vet. Med. Sci. 61: 1027-1031.

5. Endo, H., Nishiumi, I., Hayashi, Y., Rashdi, A. B. M., Nadee, N., Nabhitabhata, J., Kawamoto, Y., Kimura, J., Nishida, T. and Yamada, J. 2000. J. Vet. Med. Sci. 62: 375-378.

6. Kock, D. and Posamentier, H. 1985. Z. Säugetierkunde 51: 146-152.

7. Lyon, M. W. 1913. Proc. U. S. Natn. Mus. 45: 1-183.

Table 1. Composition of locality, sex and variation in skull specimens

\begin{tabular}{|c|c|c|c|c|c|}
\hline \multirow[t]{2}{*}{ Origin of Specimens } & \multicolumn{2}{|c|}{ Male } & \multicolumn{2}{|c|}{ Female } & \multirow[t]{2}{*}{ Total } \\
\hline & Grayish & Reddish & Grayish & Reddish $^{\text {a) }}$ & \\
\hline Hat-Yai & 2 & 3 & 1 & 1 & 7 \\
\hline Northern locality ${ }^{\mathrm{b})}$ & \multicolumn{2}{|c|}{50} & \multicolumn{2}{|c|}{50} & 100 \\
\hline Southern locality ${ }^{\text {b) }}$ & \multicolumn{2}{|c|}{22} & \multicolumn{2}{|c|}{37} & 59 \\
\hline Total & & & & & 166 \\
\hline
\end{tabular}

a) The skin color type was identified by the external observation of the present 7 materials from Hat-Yai.

b) These specimens have been stored in several museums as shown in the text. The skin color was not examined in these specimens. 


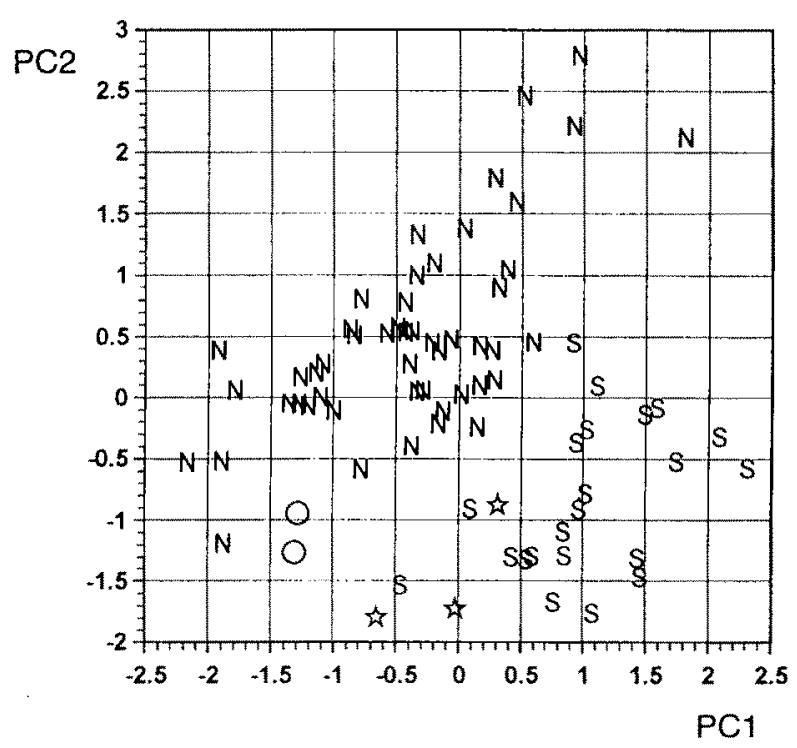

Fig. 2. The principal component chart of male skulls between the first and second transformed variables from 17 measurement items. N, plots of the museum specimens from northern localities. S, plots from southern localities. $\bigcirc$, grayish type materials from Hat-Yai. is, reddish type individuals from HatYai. PC1, the first principal component. PC2, the second principal component. The percentage of the variation explained by $\mathrm{PC} 1$ is 60.7 , and that by $\mathrm{PC} 2$ is 11.8 . The items, which largely contribute to the first principal component, are length from the condyle, profile length, and length from the angle in higher ranking, and to the second principal component, are height of the mandible at $\mathrm{M}_{1}$, length from Basion to Staphylion, and greatest palatal breadth.

8. Toder, R., von Holst, D. and Schempp, W. 1992. Cytogenet. Cell Genet. 60: 55-59.

9. Wilson, D. E. and Reeder, D. A. 1993. Mammal Species of the

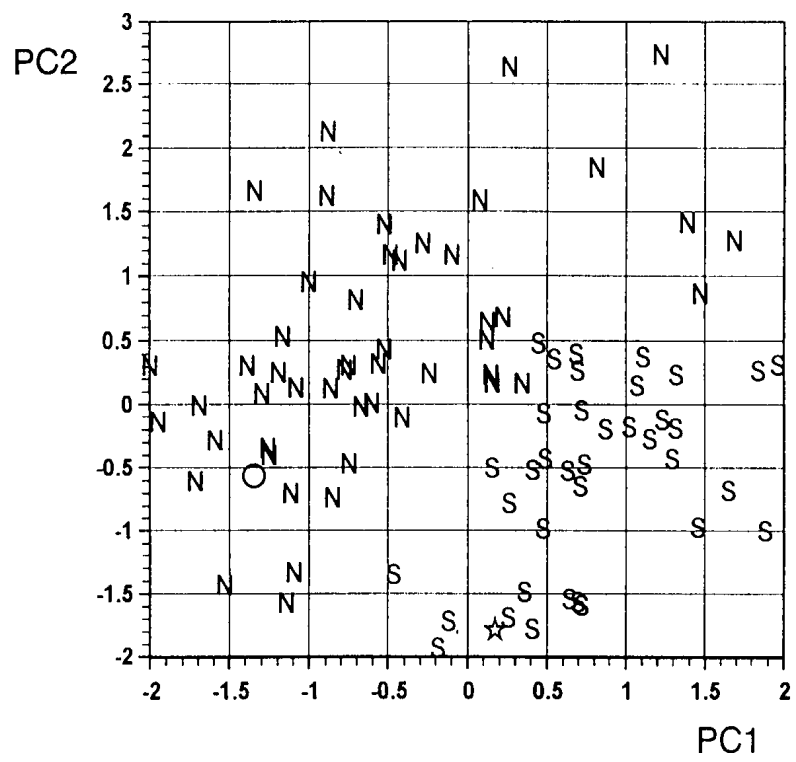

Fig. 3. The principal component chart of female skulls between the first and second transformed variables from 17 measurement items. N, plots of the museum specimens from northern localities. S, plots from southern localities. $\bigcirc$, grayish type materials from Hat-Yai. is, reddish type individuals from Hat-Yai. PC1, the first principal component. $\mathrm{PC} 2$, the second principal component. The percentage of the variation explained by $\mathrm{PC} 1$ is 63.0 , and that by PC2 is 8.8. The items, which largely contribute to the first principal component, are condylobasal length, length from the condyle, and profile length in higher ranking, and to the second principal component, are height of the mandible at $\mathrm{M}_{1}$, greatest palatal breadth, and zygomatic width.

World; A Taxonomic and Geographic Reference. 2nd ed., Smithsonian Institution Press, Washington. 